\title{
Ursodeoxycholic Acid May Inhibit Deoxycholic Acid-Induced Apoptosis by Modulating Mitochondrial Transmembrane Potential and Reactive Oxygen Species Production
}

\author{
Cecilia M. P. Rodrigues, ${ }^{1,3}$ Guangsheng Fan, ${ }^{1}$ Phillip Y. Wong, \\ Betsy T. Kren, ${ }^{1}$ and Clifford J. Steer ${ }^{1,2}$ \\ Departments of ${ }^{1}$ Medicine and ${ }^{2}$ Cell Biology, University of Minnesota \\ Medical School, Minneapolis, Minnesota, U.S.A. \\ ${ }^{3}$ Instituto Superior de Ciências da Saúde-Sul, Monte da Caparica, \\ Portugal \\ Communicated by B. O'Malley. Accepted January 12, 1998.
}

\begin{abstract}
Background: The hydrophilic bile salt ursodeoxycholate (UDCA) inhibits injury by hydrophobic bile acids and is used to treat cholestatic liver diseases. Interestingly, hepatocyte cell death from bile acid-induced toxicity occurs more frequently from apoptosis than from necrosis. However, both processes appear to involve the mitochondrial membrane permeability transition (MPT). In this study, we determined the inhibitory effect of UDCA on deoxycholic acid (DCA)-induced MPT in isolated mitochondria by measuring changes in transmembrane potential $\left(\Delta \Psi_{m}\right)$ and production of reactive oxygen species (ROS). In addition, we examined the expression of apoptosis-associated proteins in mitochondria isolated from livers of bile acid-fed animals.

Materials and Methods: Adult male rats were maintained on standard diet supplemented with DCA and/or UDCA for 10 days. Mitochondria were isolated from livers by sucrose/percoll gradient centrifugation and MPT was measured using spectrophotometric and fluorimetric assays. $\Delta \Psi_{\mathrm{m}}$ and ROS generation were determined by FACScan analysis. Cytoplasmic and mitochondrial protein abundance were determined by Western blot analysis.
\end{abstract}

\begin{abstract}
Results: DCA increased mitochondrial swelling 25-fold over controls $(p<0.001)$; UDCA reduced the swelling by $>40 \%(p<0.001)$. Similarly, UDCA inhibited DCAmediated release of calcein-loaded mitochondria by $50 \%$ $(p<0.001) . \Delta \Psi_{\mathrm{m}}$ was significantly decreased in mitochondria incubated with DCA but not with UDCA. $\Delta \Psi_{\mathrm{m}}$ disruption was followed closely by increased superoxide anion and peroxides production $(p<0.01)$. Coincubation of mitochondria with UDCA significantly inhibited the changes associated with DCA $(p<0.05)$. In vivo, DCA feeding was associated with a 4.5 -fold increase in mitochondria-associated Bax protein levels $(p<0.001)$; combination feeding with UDCA almost totally inhibited this increase $(p<0.001)$.

Conclusion: UDCA significantly reduces DCA-induced disruption of $\Delta \Psi_{m}$, ROS production, and Bax protein abundance in mitochondria, suggesting both short- and long-term mechanisms in preventing MPT. The results suggest a possible role for UDCA as a therapeutic agent in the treatment of both hepatic and nonhepatic diseases associated with high levels of apoptosis.
\end{abstract}

\section{Introduction}

It is widely recognized that accumulation of hydrophobic bile acids plays a major role in liver

Address correspondence and reprint requests to: Dr. Clifford J. Steer, Department of Medicine, Box 36 UMHC, University of Minnesota Medical School, 420 Delaware Street S.E., Minneapolis, MN 55455. Phone: 612-624-6648; Fax: 612-625-5620; E-mail: steer001@maroon.tc.umn.edu injury during cholestasis (1-3). In contrast, hydrophilic bile acids such as ursodeoxycholic acid (UDCA) appear to protect against such injury (4-6). We have recently demonstrated that toxic bile acids directly induce apoptosis in liver tissue in situ (7). UDCA prevented deoxycholic acid (DCA) toxicity by a mechanism beyond the simple displacement of hydrophobic bile acids and 
including a direct effect at inhibiting apoptosis in liver tissue. In addition, UDCA was shown to significantly modulate the apoptotic threshold in hepatic and nonhepatic cells from a variety of non-bile acid-inducing agents by preventing mitochondrial membrane perturbation. These observations supported a unique role for UDCA in regulating apoptosis through a mechanism involving mitochondrial function.

Several independent studies have shown that bile acid cytotoxicity may be a consequence of mitochondrial dysfunction. In vitro, bile salts cause impaired state III respiration when added to mitochondria or permeabilized hepatocytes $(8,9)$, and ATP depletion occurs during hepatocyte necrosis (8). In vivo, swollen mitochondria are observed in bile duct-ligated rats and in humans with cholestasis (10), and mitochondria isolated from bile duct-ligated rats also have impaired state III respiration (11). Moreover, mitochondrial dysfunction during hepatocyte necrosis appears to be a consequence of an increase in mitochondrial membrane permeability transition (MPT) $(12,13)$. The MPT may occur by two mechanisms involving nonspecific injury to the membrane lipids or opening of a multiprotein pore complex in the inner mitochondrial membrane. As a consequence of MPT, the mitochondrial transmembrane potential $\left(\Delta \Psi_{\mathrm{m}}\right)$ collapses, thereby uncoupling the respiratory chain and inhibiting ATP biosynthesis. This results in production of reactive oxygen species (ROS), including superoxide anion and peroxides, and subsequent release of inner mitochondrial membrane proteins $(14,15)$. Opening of the permeability transition pore may be influenced by multiple parameters, many of which are associated with apoptosis. These include ROS production, primary activation of ICE-like caspases, modification of the Bcl-2 complex, and sustained increases in cytosolic calcium levels, resulting in a self-amplifying cascade (15). Additionally, a reduction of $\Delta \Psi_{m}$ and production of ROS were recently shown to play a major role during Baxinduced cell death (16).

A common event in apoptosis, regardless of the inducing signal and cell type, appears to be the disruption of mitochondrial function. It may, in fact, mark an almost irreversible commitment to cell death by apoptosis (15). Since previous work had suggested that UDCA inhibited mitochondrial membrane damage from other hydrophobic bile salts (17), we isolated mitochondria from rat livers to determine whether DCA induces the MPT associated with mitochondrial membrane dysfunction in apoptosis. Then, to establish whether the role of UDCA in modulating DCA-induced apoptosis was related to its ability to inhibit MPT, we measured $\Delta \Psi_{\mathrm{m}}$ and ROS production in isolated mitochondria. Finally, apart from two recent reports showing de novo expression of the anti-apoptotic protein Bcl-2 in hepatocytes from bile duct-ligated rats (18) and patients with primary biliary cirrhosis (19), little is known about the effect of bile acids on apoptosis-related proteins. We therefore characterized apoptosis-related hepatic gene expression in bile acid-fed animals.

The results indicated that UDCA significantly reduced $\Delta \Psi_{\mathrm{m}}$ disruption and ROS production associated with DCA in isolated mitochondria, suggesting a possible explanation for its role in preventing MPT. Moreover, the mitochondrial perturbation by DCA was associated with significant modulation of apoptosis-related protein abundance in mitochondrial membranes, possibly altering their channel-forming activity. The study demonstrates that at least one direct mechanism by which UDCA significantly inhibits DCA-induced apoptosis is by preventing MPT.

\section{Materials and Methods}

\section{Animals and Diets}

Male 160-175 g Sprague-Dawley rats (SpragueDawley, Indianapolis, IN) were maintained on a 12-hr light-dark cycle and fed standard laboratory chow ad libitum for 3 days. The animals were then transferred to metabolic cages and fed diets of standard laboratory chow supplemented with either no bile acid or $0.4 \%$ (wt/wt) DCA, $0.4 \%$ UDCA, or a combination of DCA + UDCA (Bio-Serv, Frenchtown, NJ). On day 10, the animals were sacrificed by exsanguination under ether anesthesia between 9 and 11 A.M. The livers were removed, rinsed in normal saline, and flash-frozen in liquid nitrogen until Western blot analyses of apoptosis-related proteins were performed. All animals received humane care in compliance with the Guide for the Care and Use of Laboratory Animals, prepared by the National Academy of Sciences (NIH Publication No. 8623, revised 1985).

\section{Mitochondrial Isolation}

Low-calcium liver mitochondria were isolated from adult male 200-250 g Sprague-Dawley rats as previously published $(17,20)$. In short, ani- 
mals were sacrificed by exsanguination under ether anesthesia and the livers removed and rinsed in normal saline. Approximately $10 \mathrm{~g}$ of minced liver was homogenized in an ice-cold solution of $70 \mathrm{mM}$ sucrose, $220 \mathrm{mM}$ mannitol, $1 \mathrm{mM}$ ethylene glycol bis ( $\beta$-aminoethylether) $-N$, $N, N^{\prime}, N^{\prime}$-tetraacetic acid (EGTA) and $10 \mathrm{mM}$ HEPES, $\mathrm{pH} 7.4$, as a $10 \%(\mathrm{wt} / \mathrm{vol})$ homogenate. After 2 low-speed centrifugations, a crude mitochondrial pellet was purified by sucrose-percoll gradient centrifugation (21). The pellet was resuspended in $2 \mathrm{ml}$ of homogenate buffer, and $1 \mathrm{ml}$ of the resuspended pellet was carefully layered onto a 35 -ml self-generating gradient containing $0.25 \mathrm{M}$ sucrose, $1 \mathrm{mM}$ EGTA and percoll $(75: 25, \mathrm{vol} / \mathrm{vol})$. The mitochondria were purified by centrifugation at $43,000 \times g$ for $30 \mathrm{~min}$ at $4^{\circ} \mathrm{C}$ using a Beckman Ti60 rotor and a Beckman ultracentrifuge model L8-55 (Beckman Instruments, Inc., Schaumburg, IL). The clear supernatant solution was removed and the lower turbid layer was resuspended in $30 \mathrm{ml}$ of wash buffer containing $0.1 \mathrm{M} \mathrm{KCl}, 5 \mathrm{mM} \mathrm{3-(N-morpholino)-}$ propane sulfonic acid (MOPS), and 1 mM EGTA, at $\mathrm{pH} 7.4$, and centrifuged at $7000 \times g$ for $10 \mathrm{~min}$ at $4^{\circ} \mathrm{C}$. A final wash was carried out in chelex100-treated buffer (Bio-Rad Laboratories, Hercules, CA) without EGTA. The pellet was suspended in $4 \mathrm{ml}$ of chelex-100-treated resuspension buffer containing $125 \mathrm{mM}$ sucrose, $5 \mathrm{mM}$ HEPES, $50 \mathrm{mM} \mathrm{KCl}$, and $2 \mathrm{mM} \mathrm{KH}_{2} \mathrm{PO}_{4}$. The usual yield of mitochondria was approximately $25 \mathrm{mg}$ of protein per gram of liver tissue.

\section{Marker Enzyme and Protein Analysis}

Mitochondrial fractions were analyzed for mitochondrial malate dehydrogenase (22), lysosomal $N$-acetyl- $\beta$-glucosaminidase (23), and microsomal esterase (24) enzymes as described previously. Protein concentrations were determined using the Bio-Rad protein assay (Bio-Rad Laboratories) as recommended by the manufacturer. Mitochondrial preparations were also examined for purity by phase-contrast microscopy.

\section{Spectrophotometric and Fluorimetric Assays of MPT}

The MPT was assessed using a spectrophotometric assay measuring high-amplitude rapid changes in mitochondrial volume, and a fluorimetric assay quantitating the release of calcein from calcein-loaded mitochondria. The MPT was measured spectrophotometrically as previously described $(13,17)$. Briefly, mitochondria (3 mg protein) were incubated in $3 \mathrm{ml}$ of chelex-100treated respiration buffer $(0.1 \mathrm{M} \mathrm{NaCl}, 10 \mathrm{mM}$ MOPS, pH 7.4) for $10 \mathrm{~min}$ at $25^{\circ} \mathrm{C}$ and monitored at $540 \mathrm{~nm}$ in a Beckman DU 64 spectrophotometer. Basal values of mitochondrial absorbance were measured for $5 \mathrm{~min}$, and the optical density was monitored for an additional 5 min after addition of increasing concentrations of DCA $(50-200 \mu \mathrm{M})$ or $80 \mu \mathrm{M}$ phenylarsine oxide (PhAsO; Sigma Chemical Co., St. Louis, MO). For the coincubation studies, mitochondria were preincubated with UDCA $(100-500 \mu \mathrm{M})$ or 500 $\mu \mathrm{M}$ hyodeoxycholic acid (HDCA; Sigma Chemical Co.) for $5 \mathrm{~min}$ at $25^{\circ} \mathrm{C}$ prior to initiation of the assay. The inhibition of MPT by cyclosporine A (Sigma Chemical Co.) was determined as described previously (17).

The fluorimetric assay was performed after loading the mitochondria with $10 \mu \mathrm{M}$ calceinacetoxymethyl ester (AM) (Molecular Probes Inc., Eugene, OR) for $30 \mathrm{~min}$ at $37^{\circ} \mathrm{C}$ in chelex100 -treated resuspension buffer before purification by sucrose-percoll gradient centrifugation (17). The assays were performed using calceinloaded isolated mitochondria (1 mg protein $/ \mathrm{ml}$ ) in chelex-100-treated respiration buffer at $37^{\circ} \mathrm{C}$. For the coincubation assays, the samples were preincubated for $10 \mathrm{~min}$ with $500 \mu \mathrm{M}$ UDCA prior to addition of $200 \mu \mathrm{M}$ DCA. The fluorescence of calcein was monitored by excitation and emission wavelengths of 490 and $515 \mathrm{~nm}$, respectively, using a Perkin-Elmer luminescence spectrometer model LS-5B (Perkin-Elmer Ltd., Buckinghamshire, England).

\section{Measurement of $\Delta \Psi_{m}$ and ROS Production by FACS Analysis}

$\Delta \Psi_{\mathrm{m}}$ and ROS production were measured by FACScan (Becton Dickinson, San Jose, CA) analysis. Freshly isolated rat mitochondria were resuspended in respiration buffer $(50-100 \mu \mathrm{g} / \mathrm{ml})$ and then incubated for $15 \mathrm{~min}$ at $37^{\circ} \mathrm{C}$ with $50 \mathrm{nM}$ 3,3'-dihexyloxacarbocyanine iodide $\left[\operatorname{DiOC}_{6}(3)\right], 2 \mu \mathrm{M}$ dihydroethidium (HE), or 5 $\mu \mathrm{M} 2^{\prime}, 7^{\prime}$-dichlorofluorescin diacetate $\left(\mathrm{H}_{2} \mathrm{DCFDA}\right.$; Molecular Probes Inc.) (25-27). Mitochondria were then treated with DCA $(100 \mu \mathrm{M})$ or PhAsO $(80 \mu \mathrm{M})$ for $5 \mathrm{~min}$ and analyzed by cytofluorometry. For the coincubation studies, mitochondria were preincubated with UDCA $(500 \mu \mathrm{M})$ or HDCA $(500 \mu \mathrm{M})$ prior to the addition of either DCA or PhAsO. 
Table 1. Enzymatic activities in fractionated mitochondria

\begin{tabular}{llcr}
\hline & \multicolumn{2}{c}{ Specific Activity $^{a}$} & \\
\cline { 2 - 3 } Enzymes & Homogenate & Pellet & Relative Enrichment $^{b}$ \\
\hline Malate dehydrogenase & $1.14 \pm 0.25$ & $4.05 \pm 0.25$ & $3.64 \pm 0.44$ \\
$N$-acetyl- $\beta$-glucosaminidase & $1.25 \pm 0.12$ & $0.68 \pm 0.17$ & $0.56 \pm 0.13$ \\
Microsomal esterase & $0.50 \pm 0.04$ & $0.07 \pm 0.01$ & $0.14 \pm 0.06$ \\
\hline
\end{tabular}

Mitochondria were isolated from rat liver by sucrose-percoll gradient centrifugation as described in Materials and Methods. Data are mean \pm standard deviation (S.D.) from at least three different experiments.

${ }^{a}$ Specific activity represents units of enzyme activity/mg protein for malate dehydrogenase and microsomal esterase. Specific activity for $N$-acetyl- $\beta$-glucosaminidase represents milliunits of enzymatic activity/mg protein.

${ }^{b}$ Relative enrichment represents the specific activity for the respective enzyme in the pellet relative to the specific activity in the homogenate.

Western Blot Analysis

Cytoplasmic proteins were isolated from rat liver tissue as described previously (28). Briefly, frozen liver tissue from bile acid-fed rats was ground to a powder in liquid nitrogen using a mortar and pestle followed by Dounce homogenization in hypotonic buffer containing $10 \mathrm{mM}$ Tris, $\mathrm{pH} 7.6,5 \mathrm{mM} \mathrm{MgCl}_{2}, 1.5 \mathrm{mM} \mathrm{KAc}$, and $2 \mathrm{mM}$ dithiothreitol (DTT), supplemented with the Complete ${ }^{\mathrm{TM}}$ protease inhibitor cocktail (Boehringer Mannheim Biochemicals, Inc., Indianapolis, IN) at $4^{\circ} \mathrm{C}$. Total liver lysate obtained by Dounce homogenization was centrifuged at $4^{\circ} \mathrm{C}$ for $10 \mathrm{~min}$ at $500 \times g$ and the resulting supernatant was centrifuged a second time. Mitochondria were isolated from frozen liver tissue as described above using buffers supplemented with the protease inhibitor cocktail. Cytoplasmic and mitochondrial protein concentrations were determined using the Bio-Rad protein assay (Bio-Rad Laboratories). Proteins were separated using 15\% (30:0.2) SDS-PAGE and electrophoretically transferred to nitrocellulose membrane. The membranes were processed for protein detection using the ECLTM system from Amersham Life Science, Inc. (Arlington Heights, IL) as described previously (28). The primary antibodies used were: Bax-polyclonal sc-6236; p53-monoclonal sc-99; c-Myc-polyclonal sc-764 (Santa Cruz Biotechnology, Inc., Santa Cruz, CA); Bad-monoclonal B36420; Bcl-2-monoclonal B46620; Bcl- $\mathrm{X}_{\mathrm{L}}$-polyclonal B22630 (Transduction Laboratories, Lexington, $\mathrm{KY}$ ); and $\mathrm{Rb}$ monoclonal XZ161 (Dr. Ed Harlow, Boston, MA).

\section{Densitometry}

Video densitometry was accomplished using a Macintosh II (Apple Computer, Cupertino, CA) coupled to a Data Translation DT2255 video digitizer (Data Translation, Marlboro, MA) and a JVC GX-N8 video camera (JVC Corporation of America, Elmwood Park, NJ) as described previously (29). Quantitation of the autoradiograms was performed using the NIH Image 1.4 densitometric analysis program.

\section{Statistical Analysis}

Statistical analysis was performed using InStat version 2.1 for the ANOVA and Bonferroni's multiple comparison tests. Unless otherwise indicated, results are expressed as mean values \pm standard deviation (S.D.).

\section{Results}

\section{UDCA Inhibits DCA-Induced MPT}

Phase-contrast microscopy of the isolated mitochondria indicated that they were intact, free of contamination and exhibited minimal clumping. In addition, the purity of the isolated mitochondrial fraction was assessed by marker enzyme studies. As shown in Table 1, the purified mitochondrial pellet was highly enriched in mitochondrial malate dehydrogenase activity with minimal contamination by lysosomal $N$-acetyl$\beta$-glucosaminidase or microsomal esterase activity. Having established the authenticity of the mitochondrial fraction, the MPT was measured 
A



FIG. 1. MPT changes in isolated rat liver mitochondria incubated with bile acids. Mitochondria were isolated and incubated (l $\mathrm{mg}$ protein $/ \mathrm{ml}$ ) with either DCA, UDCA, DCA + UDCA, or no bile acid (control) in respiration buffer as described in Materials and Methods. (A) Percent change in mitochondrial swelling was measured by monitoring the optical density at $540 \mathrm{~nm}$. At time zero, $200 \mu \mathrm{M}$ DCA was added and swelling was monitored for an additional $5 \mathrm{~min}$. In the coincubation experiments, mitochondria were preincubated with $500 \mu \mathrm{M}$

using spectrophotometric and fluorimetric methods (Fig. 1 A, B). It has been previously reported that incubation with glycochenodeoxycholic acid resulted in hepatocyte toxicity (8) and induced MPT in isolated rat liver mitochondria $(17,30)$. In this study, incubation with DCA also induced significant changes in the MPT of isolated hepatic mitochondria (Fig. 1A). Mitochondrial swelling increased 25-fold over control values after a 5 -min incubation with DCA $(p<0.001)$. In contrast, incubation with UDCA alone produced no significant changes in permeability relative to control values. Moreover, coincubation with UDCA protected against DCA-induced mitochondrial swelling by $>40 \%(p<0.001)$. Membrane permeability was also assessed using calcein-loaded mitochondria. In fact, incubation with DCA resulted in significant unquenching of calcein fluorescence, indicative of increased mitochondrial leakage (Fig. IB). Coincubation with UDCA inhibited DCA-induced calcein release from mitochondria by almost $50 \%(p<0.001)$, which is in agreement with the observed inhibition of mitochondrial swelling.

The dose-response effect of DCA on MPT was examined and is shown in Figure 2A. Incubation with DCA resulted in high-amplitude mitochondrial swelling that was rapid and dose dependent. The observed MPT increased from

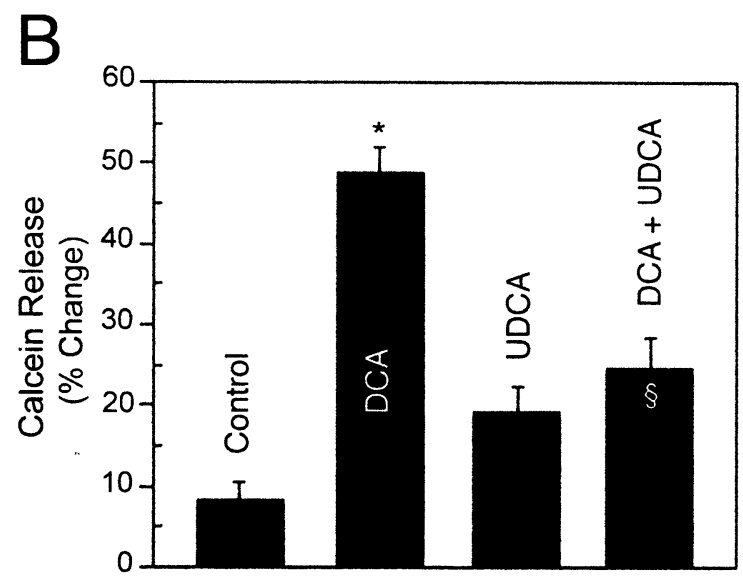

UDCA for $5 \mathrm{~min}$. (B) Percent change in calcein release from calcein-loaded mitochondria was measured by monitoring the fluorescence using excitation and emission wavelengths of 490 and $515 \mathrm{~nm}$, respectively. At time zero, $200 \mu \mathrm{M}$ DCA was added and fluorescence was monitored for an additional 20 min. In the coincubation experiments, mitochondria were pretreated with $500 \mu \mathrm{M}$ UDCA for $10 \mathrm{~min}$. Values are mean \pm standard deviations (S.D.) of at least five different experiments. ${ }^{*} p<0.001$ from controls; ${ }^{s_{p}}<0.001$ from DCA.

4-fold over controls after incubation with $50 \mu \mathrm{M}$ to greater than 25 -fold after incubation with $200 \mu$ M DCA $(p<0.001)$. Significant inhibition of the DCA-induced MPT by $500 \mu \mathrm{M}$ UDCA occurred in both the $100(p<0.05)$ and $200 \mu \mathrm{M}$ DCA $(p<0.001)$ treatment groups. Additionally, UDCA inhibited the DCA-induced MPT in a concentration-dependent fashion (Fig. 2B). When mitochondria suspended in respiration buffer were preincubated with increasing concentrations of UDCA for $5 \mathrm{~min}$ prior to the addition of $200 \mu \mathrm{M}$ DCA, swelling decreased from $26.8 \pm$ $6.3 \%$ with $100 \mu \mathrm{M}$ UDCA to $16.9 \pm 2.3 \%$ with $500 \mu \mathrm{M}$ UDCA $(p<0.001)$. The addition of UDCA after incubation with DCA did not result in significant reversal of MPT (data not shown). We then determined whether the inhibition of the DCA-induced MPT by UDCA was bile acid specific or simply a property of hydrophilicity. To address this issue, isolated mitochondria were incubated with a similarly hydrophilic bile acid HDCA. Interestingly, pretreatment of the isolated hepatic mitochondria with $500 \mu \mathrm{M}$ HDCA did not decrease DCA-induced mitochondrial swelling (Fig. 2B) or prevent calcein release.

The significant mitochondrial swelling observed after incubation with DCA suggested that the observed MPT resulted from perturbation of the cyclosporine $\mathrm{A} /$ trifluoperazine-sensitive in- 


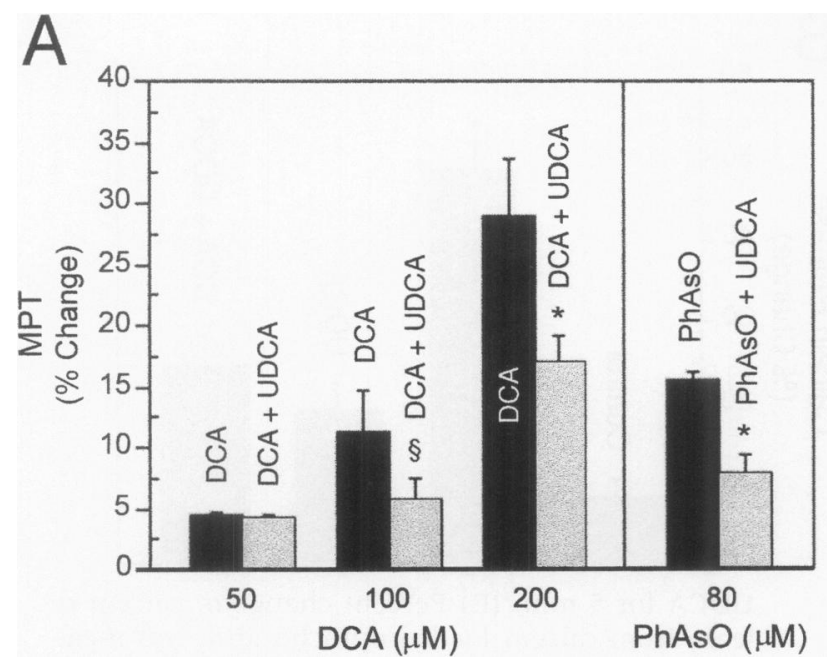

FIG. 2. Dose-response of isolated mitochondria to bile acid-induced MPT. Mitochondria were isolated and incubated (1 mg protein $/ \mathrm{ml}$ ) with either DCA, DCA + UDCA, PhAsO, PhAsO + UDCA, HDCA, or DCA + HDCA in respiration buffer as described in Materials and Methods. Percent change in MPT was measured by monitoring mitochondrial swelling. (A) Dose-response to DCA. At time zero, $50-200 \mu \mathrm{M}$ DCA or $80 \mu \mathrm{M}$ PhAsO was added and mitochondrial swelling was monitored for an additional $5 \mathrm{~min}$. In the coincubation experi-

ner membrane large conductance channels (megapores), rather than nonspecific membrane disruption (13,31). In fact, earlier studies showed that pretreatment of mitochondria with cyclosporine A and/or trifluoperazine inhibited swelling induced by glycine conjugated chenodeoxycholic acid (17). These observations suggested that UDCA was interacting directly with the mitochondrial membrane and that it might be a general inhibitor of this form of MPT. To test this premise, we incubated isolated mitochondria with either PhAsO, a known inducer of the megapore opening form of MPT $(13,31)$, or a combination of PhAsO plus UDCA. When mitochondria were coincubated with $500 \mu \mathrm{M}$ UDCA and $80 \mu \mathrm{M}$ PhAsO, the MPT was reduced by approximately $50 \%$ compared with $\mathrm{PhAsO}$ alone $(p<0.001)$ (Fig. 2A). Moreover, DCA-induced mitochondrial swelling was inhibited by $>45 \%$ with $5 \mu \mathrm{M}$ cyclosporine $\mathrm{A}$, a known inhibitor of the megapore channel. Finally, coincubation with both UDCA and cyclosporine did not produce an additive effect, suggesting that they inhibited MPT by similar mechanisms. Thus, the data indicate that both the induction of MPT by DCA and its inhibition by UDCA in isolated rat liver mitochondria are dose dependent. More-

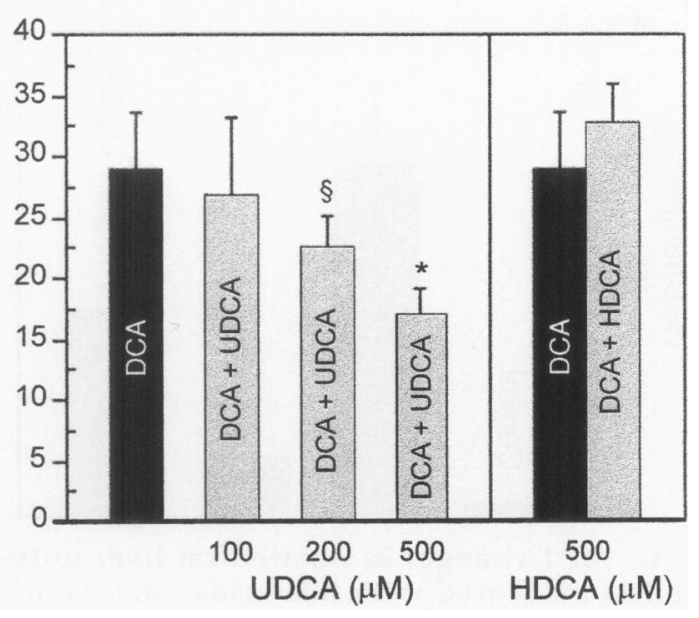

ments, mitochondria were preincubated with 500 $\mu \mathrm{M}$ UDCA for $5 \mathrm{~min}$. (B) Dose-response to UDCA. At time zero, $200 \mu \mathrm{M}$ DCA was added and mitochondrial swelling was monitored for an additional 5 min. In the coincubation experiments, mitochondria were pretreated with $100-500 \mu \mathrm{M}$ UDCA or 500 $\mu \mathrm{M}$ HDCA for $5 \mathrm{~min}$. Values are mean \pm standard deviations (S.D.) of at least five different experiments. ${ }^{\S} p<0.05$ from DCA; ${ }^{\star} p<0.001$ from DCA or PhAsO.

over, the ability of UDCA to act as a general inhibitor of the megapore form of MPT appears to be bile acid specific and is not simply a property of its hydrophilicity.

\section{UDCA Inhibits Disruption of $\Delta \Psi_{m}$ and ROS Production}

FACScan analysis confirmed the existence of mitochondrial perturbation during treatment of isolated mitochondria with DCA. Significant changes were detected in both $\Delta \Psi_{\mathrm{m}}$ and ROS production when isolated mitochondria were exposed to $100 \mu \mathrm{M}$ DCA for $5 \mathrm{~min}$ in the presence or absence of $500 \mu \mathrm{M}$ UDCA. As shown in Figure $3 \mathrm{~A}$, the percentage of low $\Delta \Psi_{\mathrm{m}}$ was increased after DCA treatment $(16.0 \pm 1.8 \%$ vs. $13.1 \pm 2.4 \%)$. Incubation with UDCA alone produced no significant changes in $\Delta \Psi_{\mathrm{m}}$ compared with controls. Moreover, UDCA protected against the DCA-induced increase in the percentage of low $\Delta \Psi_{\mathrm{m}}(10.3 \pm 0.7 \% ; p<0.05)$. Disruption of $\Delta \Psi_{\mathrm{m}}$ with DCA was closely followed by an increased production of the ROS superoxide anion, as measured by dihydroethidium oxidation to ethidium (Fig. 3B). Superoxide anion production was significantly increased after DCA 

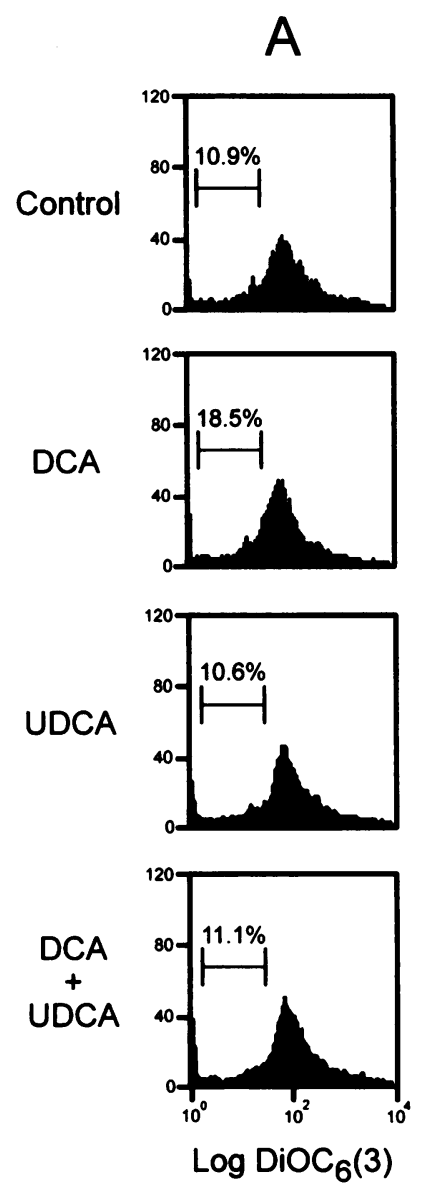
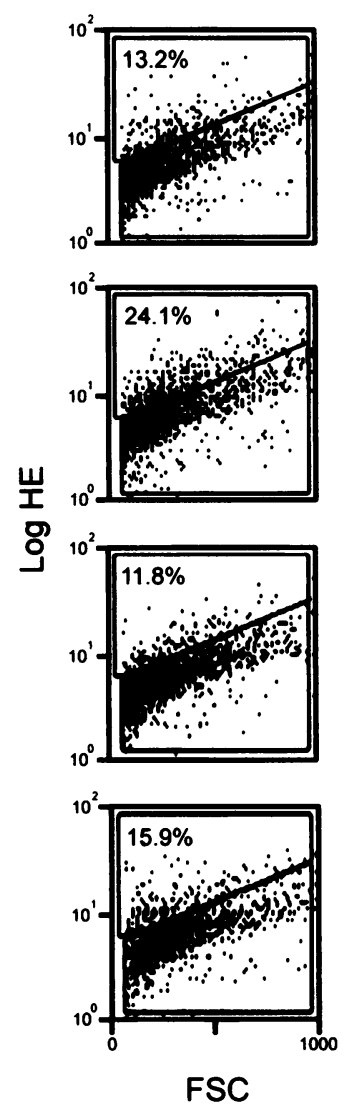
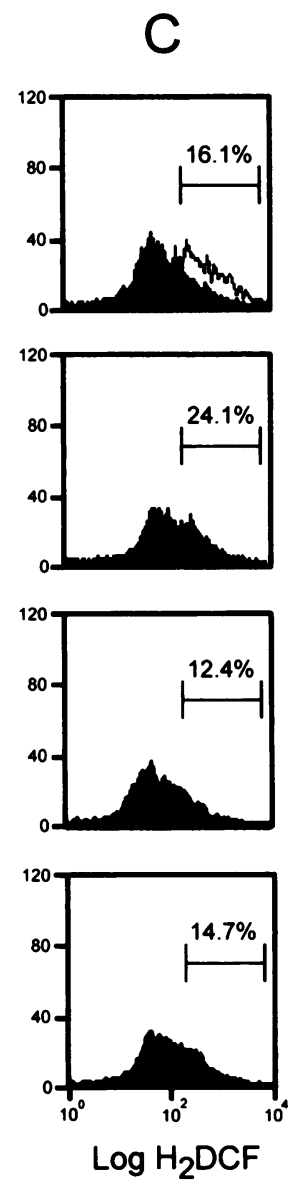

FIG. 3. Reduction of $\Delta \Psi_{m}$ and increased production of ROS after incubation of isolated mitochondria with DCA. Isolated mitochondria were incubated with $100 \mu \mathrm{M}$ DCA, $500 \mu \mathrm{M}$ UDCA, $100 \mu \mathrm{M}$ DCA $+500 \mu \mathrm{M}$ UDCA, or no bile acid addition (control) for 5 min. In the coincubation experiments, mitochondria were pretreated with UDCA alone for 5 min prior to addition of DCA. Isolated mitochondria (1 mg protein $/ \mathrm{ml}$ ) were suspended in respiration buffer and incubated for $15 \mathrm{~min}$ at $37^{\circ} \mathrm{C}$ with $50 \mathrm{nM}$ $\mathrm{DiOC}_{6}(3), 2 \mu \mathrm{M} \mathrm{HE}$, or $5 \mu \mathrm{M}$ $\mathrm{H}_{2}$ DCFDA and analyzed by cytofluorometry. The percentages reflect (A) the disruption in $\Delta \Psi_{\mathrm{m}} ;$ (B) the increased production of superoxides; and $(C)$ the increased production of peroxides during treatment with DCA, and the respective inhibition by UDCA. The treatment groups are indicated on the left; the open peak in the control group panel $\mathrm{C}$ shows a positive control after incubation with 10 $\mathrm{mM} \mathrm{H}_{2} \mathrm{O}_{2}$. The data shown are representative of at least three different experiments. Coincubation with UDCA was associated with significant inhibition of mitochondrial perturbation $(p<0.05$, or lower $)$.

treatment $(20.7 \pm 2.4 \%$ vs. $13.8 \pm 0.8 \% ; p<$ $0.01)$ and slightly decreased after UDCA incubation alone $(11.8 \pm 2.8 \%)$. Furthermore, UDCA inhibited the production of superoxides induced by DCA $(15.9 \pm 1.5 \% ; p<0.05)$. Generation of other ROS, including hydrogen peroxide and hydroxyl radical measured using $\mathrm{H}_{2}$ DCFDA, was also substantially increased during DCA incubation compared with untreated mitochondria (Fig. 3C). Conversely, incubation with UDCA alone slightly decreased the percentage of other ROS. When the two bile acids were combined, UDCA completely prevented the changes associated with the hydrophobic bile acid (21.7 \pm $3.5 \%$ vs. $14.7 \pm 1.4 \% ; p<0.05)$.

When mitochondria were coincubated with $500 \mu \mathrm{M}$ UDCA, $\Delta \Psi_{\mathrm{m}}$ disruption was reduced by approximately $65 \%$ when compared with $80 \mu \mathrm{M}$ $\mathrm{PhAsO}$ alone (Fig. 4A). Similarly, ROS production of superoxide anions and peroxides were

reduced $100 \%$ and $55 \%$, respectively, (Fig. $4 \mathrm{~B}$, C) when UDCA was coincubated with PhAsO $(p<0.05$, or lower). In contrast, coincubation of isolated mitochondria with $500 \mu \mathrm{M}$ HDCA did not prevent DCA-mediated changes in $\Delta \Psi_{\mathrm{m}}$ (Fig. 5A) and ROS production (Fig. 5B, C). Also, no changes were observed with HDCA alone.

\section{Modulation of Apoptosis-Related Protein Expression with Bile Acid Feeding}

To examine the potential chronic effect of bile acids on apoptosis-associated gene expression, we determined liver cytoplasmic and mitochondrial steady-state protein levels for $\mathrm{Bcl}-2, \mathrm{Bcl}-\mathrm{X}_{\mathrm{L}^{\prime}}$ $\mathrm{Bax}$, and Bad. Cytoplasmic levels of the proapoptotic protein Bax showed no significant change across all groups of animals regardless of whether bile acids were included in the diet (Fig. 6). In contrast, Bad expression was in- 

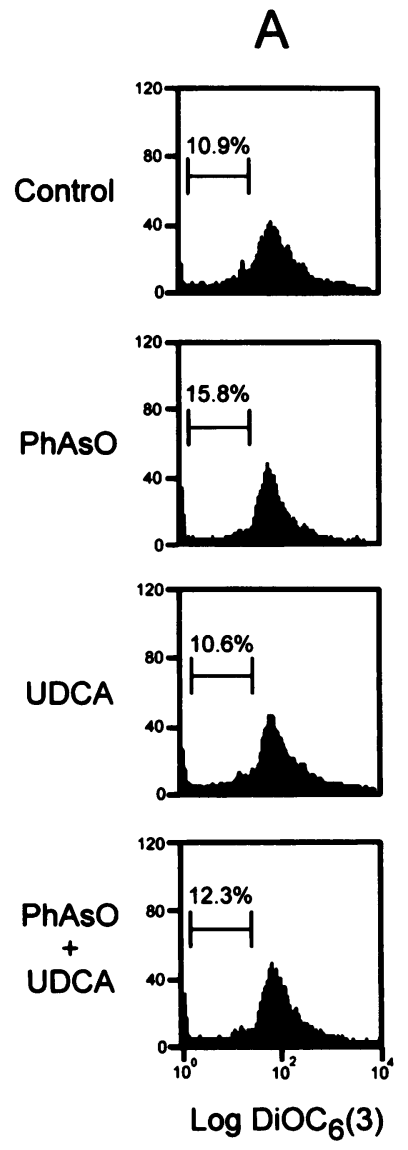

B
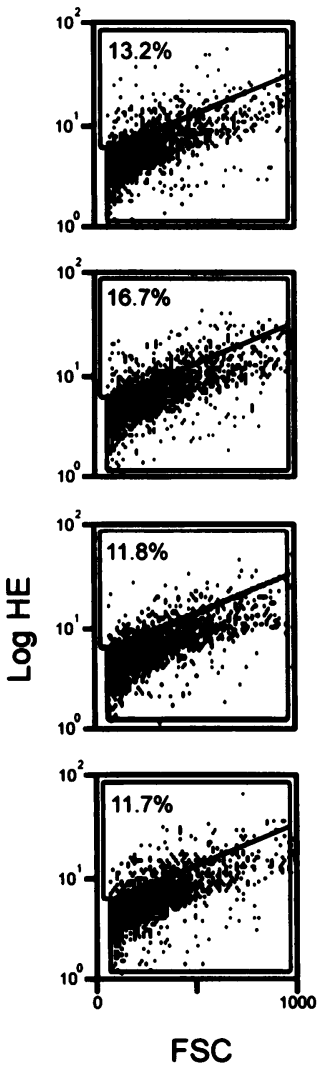

FSC

creased approximately 2 -fold with DCA. Interestingly, although UDCA alone decreased Bad expression, the combination of DCA + UDCA increased protein abundance 5 -fold $(p<0.001)$. The steady-state levels of the anti-apoptotic protein Bcl-2 remained invariant in all animals, whereas the expression of its homolog Bcl- $\mathrm{X}_{\mathrm{L}}$, increased after the administration of UDCA alone $(p<0.05)$ or when it was combined with DCA. In contrast to these results, DCA feeding was associated with a 4.5 -fold increase in mitochondrial-associated $\operatorname{Bax}(p<0.001)$ (Fig. 7). Combination feeding with UDCA prevented this dramatic change even though UDCA feeding alone increased Bax expression slightly above baseline. The pro-apoptotic protein Bad was detected in very low levels in mitochondria in all the bile acid-fed groups relative to controls. In fact, mitochondrial abundance of this protein was decreased to $<15 \%$ of control values after bile acid feeding $(p<0.001)$. The administration of DCA significantly increased the abundance of Bcl-2 in mitochondria relative to controls $(p<$

FIG. 4. Reduction of $\Delta \Psi_{m}$ and increased production of ROS after incubation of isolated mitochondria with PhAsO. Isolated mitochondria were incubated with $80 \mu \mathrm{M}$ PhAsO, $500 \mu \mathrm{M}$ UDCA, $80 \mu \mathrm{M}$ PhAsO $+500 \mu \mathrm{M}$ UDCA, or no addition (control) for $5 \mathrm{~min}$. In the coincubation experiments, mitochondria were pretreated with UDCA alone for $5 \mathrm{~min}$ prior to addition of PhAsO. Isolated mitochondria (1 mg protein $/ \mathrm{ml}$ ) were suspended in respiration buffer and incubated for $15 \mathrm{~min}$ at $37^{\circ} \mathrm{C}$ with $50 \mathrm{nM}$ DiOC $_{6}(3), 2 \mu \mathrm{M}$ HE, or $5 \mu \mathrm{M}$ $\mathrm{H}_{2}$ DCFDA and analyzed by cytofluorometry. The percentages reflect (A) the disruption in $\Delta \Psi_{\mathrm{m}} ;$ (B) the increased production of superoxides; and (C) the increased production of peroxides during treatment with $\mathrm{PhAsO}$, and the respective inhibition by UDCA. The treatment groups are indicated on the left and the data shown are representative of at least three different experiments. Coincubation with UDCA was associated with significant inhibition of mitochondrial perturbation $(p<$ 0.05 , or lower).
0.05) and UDCA $(p<0.01)$ fed animals. However, combination feeding of both bile acids decreased Bcl-2 expression to near baseline values. Finally, no significant changes were observed across all groups in mitochondrial abundance of the anti-apoptotic protein $\mathrm{Bcl}-\mathrm{X}_{\mathrm{L}}$.

We also determined liver cytoplasmic protein levels for c-Myc, p53, and retinoblastoma, as alterations in their expression levels have been associated with hepatocyte apoptosis (32). Interestingly, bile acid feeding did not induce significant changes in cytoplasmic levels of the tumor suppressor p53 (data not shown). Similarly, no significant changes in cytoplasmic c-Myc or retinoblastoma levels were detected in any of the groups relative to controls.

\section{Discussion}

The results of this study demonstrate that DCA induces MPT as well as changes in $\Delta \Psi_{m}$ and ROS production in isolated mitochondria. In contrast 

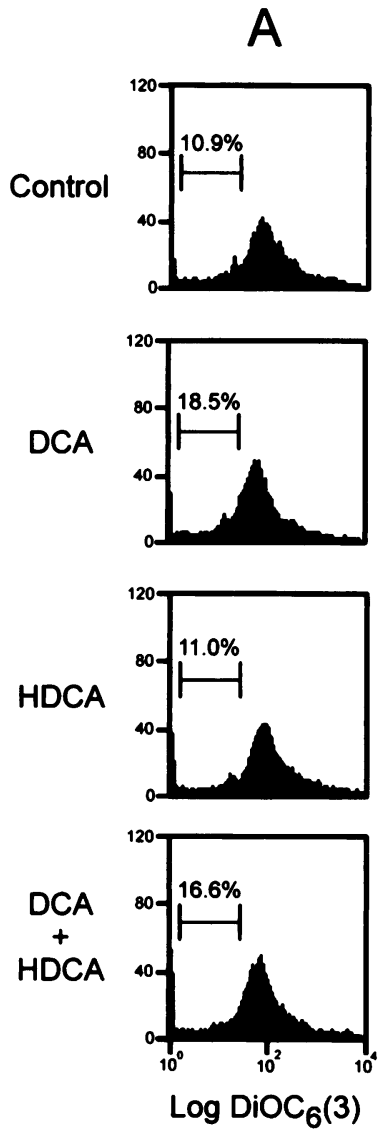

B
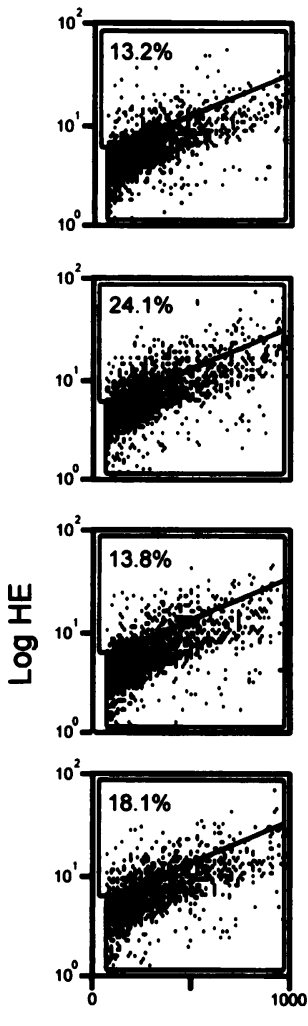

FSC
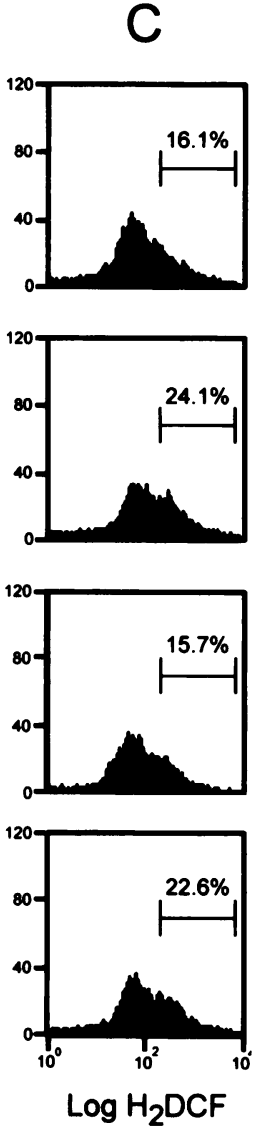

FIG. 5. HDCA does not significantly inhibit the DCAinduced reduction of $\Delta \Psi_{m}$ and increased production of ROS in isolated rat liver mitochondria. Isolated mitochondria were incubated with 100 $\mu \mathrm{M}$ DCA, $500 \mu \mathrm{M}$ HDCA, 100 $\mu \mathrm{M}$ DCA $+500 \mu \mathrm{M}$ HDCA, or no bile acid addition (control) for $5 \mathrm{~min}$. In the coincubation experiments, mitochondria were pretreated with $500 \mu \mathrm{M}$ HDCA alone for $5 \mathrm{~min}$ prior to addition of DCA. Isolated mitochondria ( $1 \mathrm{mg}$ protein $/ \mathrm{ml}$ ) were suspended in respiration buffer and incubated for $15 \mathrm{~min}$ at $37^{\circ} \mathrm{C}$ with $50 \mathrm{nM} \mathrm{DiOC}{ }_{6}(3), 2$ $\mu \mathrm{M} \mathrm{HE}$, or $5 \mu \mathrm{M} \mathrm{H}_{2}$ DCFDA and analyzed by cytofluorometry. The percentages reflect $(A)$ the disruption in $\Delta \Psi_{m} ;$ (B) the increased production of superoxides; and (C) the increased production of peroxides during treatment with DCA, and the absence of significant protection by HDCA. The data shown are representative of at least three different experiments and the treatment groups are indicated at left. to the effects of DCA, mitochondria exposed to UDCA alone exhibited no functional alterations. However, when combined with DCA, UDCA inhibited the mitochondrial changes associated with DCA. UDCA also inhibited the mitochondrial perturbation induced by $\mathrm{PhAsO}$, suggesting that UDCA may be a more general inhibitor of the megapore form of MPT. The protective effect of UDCA did not appear to be a consequence of hydrophobic-hydrophilic interactions between bile salts as the similarly hydrophilic HDCA did not inhibit MPT or prevent $\Delta \Psi_{\mathrm{m}}$ disruption and ROS production induced by DCA. Moreover, UDCA feeding completely inhibited the increased mitochondrial abundance of the pro-apoptotic protein Bax associated with DCA. This finding suggests that the increased distribution of Bax at the mitochondrial membrane in DCA-fed animals may promote the apoptotic program associated with this organelle.

The ability of UDCA to prevent DCA-induced MPT as well as changes in $\Delta \Psi_{\mathrm{m}}$ and ROS production was only somewhat less pronounced than its ability to inhibit apoptosis both in vivo and in cell culture (7). This difference, however, may result from anti-apoptotic effects of UDCA, which are independent of mitochondrial function. In this regard, it has been recently shown that the glycine-conjugated form of UDCA inhibits beauvericin-induced activity of caspase 3 , a protease involved in cholangiocyte apoptosis (33). Nevertheless, several cell-free systems have implicated mitochondria and/or mitochondrial proteins as necessary factors for apoptosis $(34,35)$. In fact, MPT is thought to be sufficient to induce both the cytosolic and nuclear events required in the apoptotic cascade (36). Moreover, it is well established that the apoptotic pathway(s) involving the different proteases and the various mitochondrial constituents are interactive. For example, Bcl-2 expression at the mitochondrial outer membrane inhibits the apoptosis induced by interleukin- $1 \beta$-converting enzyme, the mammalian homolog of the $C$. elegans cell death gene ced-3 (37). Furthermore, the addition of Bcl-2 to primed Xenopus egg extracts inhibits their ability to induce apoptotic changes in exogenously added nuclei (35).

In this study, mitochondria were isolated from rat liver to determine whether DCA induces 

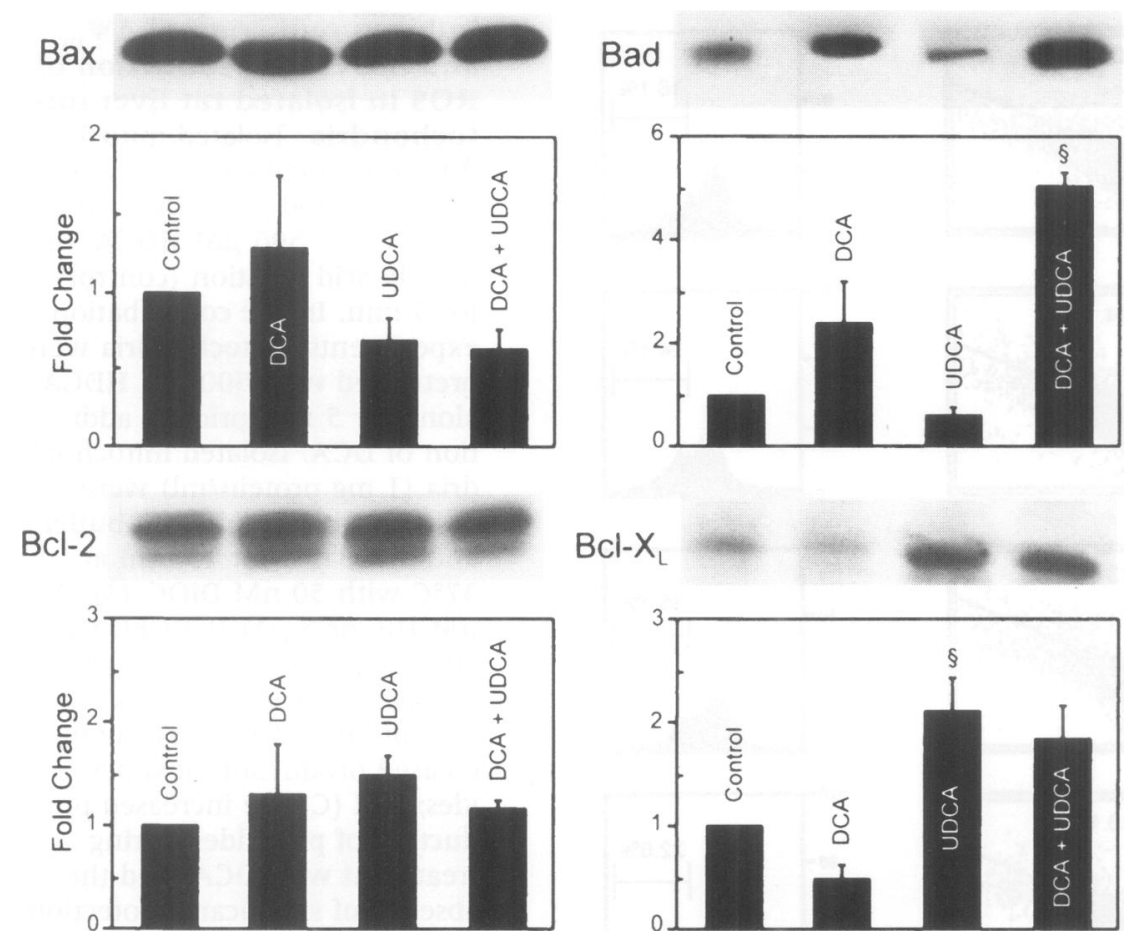

sodx.

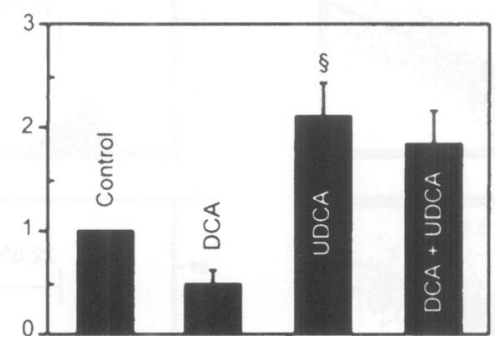

FIG. 6. Western blot analysis of apoptosis-associated proteins in liver from bile acid-fed rats. Cytoplasmic proteins (150 $\mu \mathrm{g} /$ lane) from control, DCA, UDCA, and DCA + UDCA fed rats were isolated from whole liver as described in Materials and Methods. Following SDS-PAGE and transfer, the nitrocellulose membranes were incubated with antibodies to either Bax, Bad, Bcl-2, or Bcl- $\mathrm{X}_{\mathrm{L}}$ and the proteins were detected using ECL chemiluminescence. Representative Western blots of cytoplasmic proteins are shown at the top and the accompanying histograms below depict the mean changes \pm standard error of the mean (S.E.M.) in protein levels relative to controls. The proteins are indicated on the left and the values shown are from at least three different animals from each group. ${ }^{s} p<$ 0.001 from Bad control; $p<$ 0.05 from Bcl- $\mathrm{X}_{\mathrm{L}}$ control.
MPT, and whether that perturbation was modulated by UDCA. It now appears that MPT is the earliest mitochondrial membrane event resulting in apoptosis. The results indicated that DCA induces dose-dependent high-amplitude mitochondrial swelling which is significantly inhibited by coincubation with UDCA. The specificity and ability of UDCA to act as a general inhibitor of MPT was determined using another similarly hydrophilic bile acid, HDCA, and the well-characterized MPT-inducing agent, PhAsO (13,31). The data indicated that UDCA functions as a general inhibitor of MPT and its effect on MPT was specific and not simply a result of its hydrophilicity. Moreover, the role of UDCA in modulating the apoptotic threshold in vivo and in cultured cells might be mediated in part by its protective effect on megapore function at the mitochondrial membrane.

The ability of UDCA to directly inhibit DCAinduced mitochondrial membrane perturbation was also investigated using the mitochondrial uptake of $\operatorname{DiOC}_{6}(3)$ and FACScan analysis. Isolated mitochondria treated with DCA exhibited a reduction in the uptake of fluorochrome, which acts as a marker of $\Delta \Psi_{\mathrm{m}}$ perturbation. FACScan analysis also indicated that DCA induces an increased production of superoxide anion and per- oxides measured by oxidation of $\mathrm{HE}$ and $\mathrm{H}_{2}$ DCFDA, respectively. Both $\Delta \Psi_{\mathrm{m}}$ disruption and ROS production induced by DCA were partially inhibited by coincubation with UDCA. Conversely, HDCA did not inhibit changes associated with DCA. Alterations in $\Delta \Psi_{\mathrm{m}}$ and ROS induced by $\mathrm{PhAsO}$ were also prevented by UDCA.

Taken together, these findings suggest that mitochondrial perturbation with decreased $\Delta \Psi_{\mathrm{m}}$ and enhanced ROS generation is involved in DCA-induced cell death. $\Delta \Psi_{\mathrm{m}}$ and ROS may either directly participate in cell death or occur concomitant with other mitochondrial dysfunction such as MPT. Several observations support the notion that the distribution of free ions between both sides of the mitochondrial membranes that occurs during MBT causes a collapse of $\Delta \Psi_{\mathrm{m}}$, followed by an uncoupled respiratory chain, and production of superoxide anion radicals $(14,27,38)$. Consequences of MPT such as $\Delta \Psi_{\mathrm{m}}$ disruption, apoptosis-inducing factor (AIF) and cytochrome $C$ release, and changes in redox potentials also favor MPT, thereby creating selfamplifying feedback loops. The direct inhibition of changes in $\Delta \Psi_{\mathrm{m}}$ and ROS production by UDCA suggests a beneficial effect on preventing megapore opening as changes in the mitochon- 

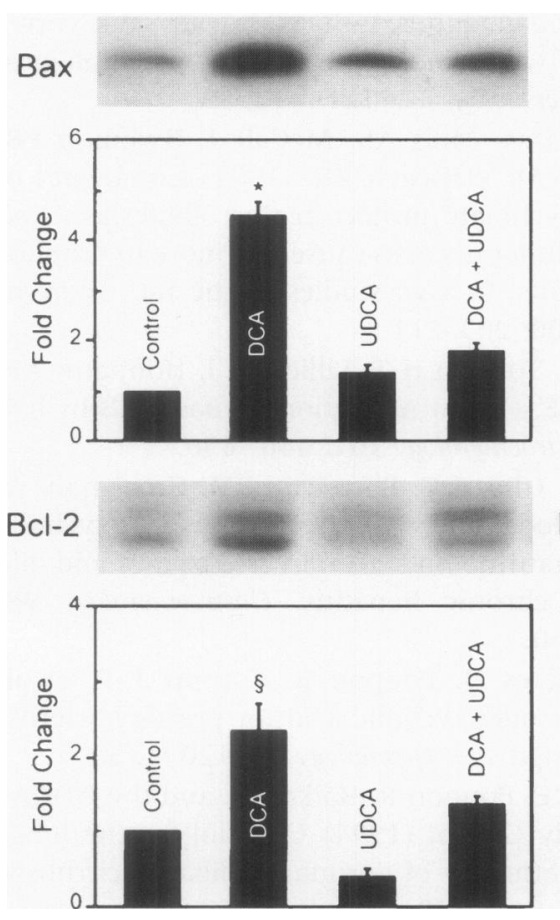
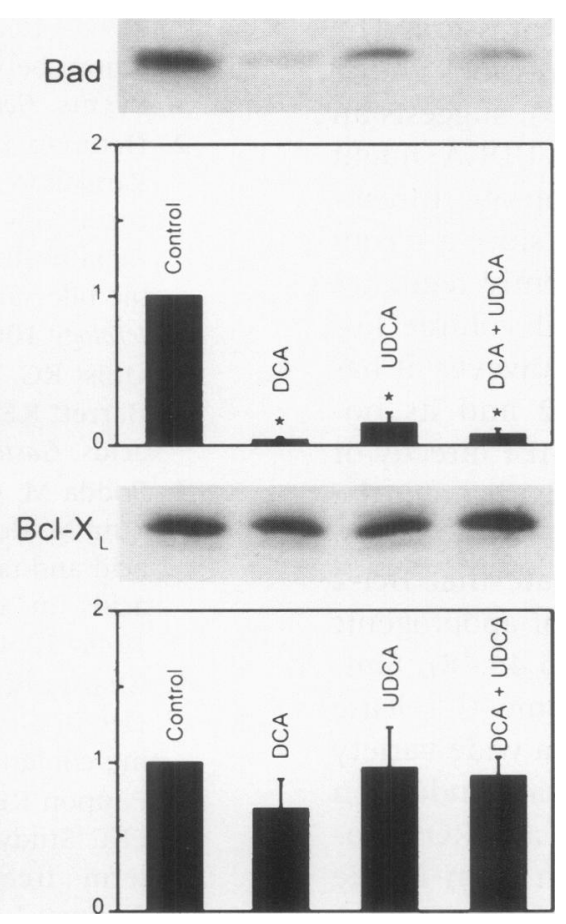

FIG. 7. Western blot analysis of apoptosis-associated proteins in mitochondria isolated from livers of bile acid-fed rats. Mitochondrial proteins (150 $\mu \mathrm{g} /$ lane) from control, DCA, UDCA, and DCA + UDCA fed rats were isolated from whole liver as described in Materials and Methods. Following SDS-PAGE and transfer, the nitrocellulose membranes were incubated with antibodies to either Bax, Bad, Bcl-2, or Bcl- $\mathrm{X}_{\mathrm{L}}$ and the proteins were detected using ECL chemiluminescence. Representative Western blots of mitochondrial proteins are shown at the top and the accompanying histograms depict the mean changes \pm S.E.M. in protein levels relative to control. The proteins are indicated on the left and the values shown are from four different animals from each group. ${ }^{*} p<0.001$ from control; $\S_{p}<0.05$ from control. drial proton electrochemical gradient alone are sufficient to induce MPT in isolated rat liver mitochondria (31). The ability of UDCA to inhibit detrimental changes in redox potentials is not without precedent. In fact, it has been demonstrated that UDCA prevents DCA-induced lipid peroxidation in cultured macrophages (39), and inhibits induction of NOS in human intestinal epithelial cells (40).

We also examined the potential chronic effect of bile acids in modulating apoptosis-related proteins. We have reported previously that bile acids do modulate gene expression in rat liver (41). For example, DCA feeding at $0.4 \%$ concentration increased expression of the p53 mRNA transcript 3-fold over control values, but decreased levels of the $4.7 \mathrm{~kb}$ transcript of the retinoblastoma gene. Steady-state mRNA expression of both tumor suppressor genes was unaffected by $0.4 \%$ UDCA, and addition of UDCA to the DCA diet completely inhibited the observed changes in transcript levels without altering the hepatic concentrations of DCA. The Western blot analyses in the present study indicate that bile acid feeding does not influence the cytoplasmic levels of the p53, c-Myc, or retinoblastoma proteins. However, DCA significantly increased protein levels of the pro-apoptotic gene product Bax at the mitochondrial membrane. Thus, the increased mitochondrial abundance of Bax in the DCA group together with the decreased levels of mitochondrial Bad observed in all groups could potentially induce apoptosis by stabilizing the formation of Bax homodimers (42). DCA feeding simultaneously increased $\mathrm{Bcl}-2$ levels in mitochondria. Interestingly, when UDCA was combined in the diet, it completely inhibited mitochondrial changes in both Bax and Bcl-2 levels associated with DCA feeding alone. These results are interesting in light of the recent report that hepatocytes in bile duct-ligated rats exhibit de novo expression of the anti-apoptotic protein $\mathrm{Bcl}-2$ (18). Immunohistochemical analysis demonstrated that $\mathrm{Bcl}-2$ was more abundant in periportal hepatocytes than pericentral hepatocytes. In contrast, the anti-apoptotic protein $\mathrm{Bcl}-\mathrm{X}_{\mathrm{L}}$ was not altered by bile duct ligation, whereas the pro-apoptotic protein Bax increased slightly by Western blot analysis. Our studies using an animal model of bile acid feeding complement the recent report that nuclear DNA fragmentation and $\mathrm{Bcl}-2$ expression was inhibited in patients with primary biliary cirrhosis treated with UDCA (19).

We also examined the effect of UDCA feeding on the cytoplasmic levels of the apoptosis- 
related genes. UDCA significantly increased cytoplasmic levels of both Bcl- $\mathrm{X}_{\mathrm{L}}$ and Bad but did not alter Bcl-2 or Bax protein expression. The substantial increase in $\mathrm{Bcl}-\mathrm{X}_{\mathrm{L}}$ expression, whose homodimers repress cell death (43), suggests an additional mechanism by which UDCA might further increase the observed apoptotic threshold. This is particularly interesting since a recent report suggests that $\mathrm{Bcl}-\mathrm{X}_{\mathrm{L}}$ apparently regulates both the membrane potential and volume homeostasis of mitochondria (44). However, it has been controversial whether Bcl-2 and its homolog Bcl- $\mathrm{X}_{\mathrm{L}}$ and Bax influence MPT directly or via an indirect mechanism, such as through the regulation of cytochrome $C$ release (45-47). Data from cell-free systems indicate that Bcl-2 can inhibit MPT and the release of apoptogenic proteins from mitochondria $(34,45,46,48)$. Similarly, Bcl- $\mathrm{X}_{\mathrm{L}}$ prevented cytochrome $\mathrm{C}$ release from mitochondria in response to a wide variety of apoptotic stimuli (44). In contrast, induction of Bax resulted in $\Delta \Psi_{\mathrm{m}}$ dissipation and ROS production, culminating in cell death even in the presence of a caspase inhibitor, which suggests that activation of caspases result from and do not induce mitochondrial perturbation (16).

In conclusion, our data support a unique role for UDCA in regulating MPT through a mechanism that may involve an interplay of events at the mitochondrial membrane. Such events appear to include direct prevention of megapore opening and/or inhibition of $\Delta \Psi_{\mathrm{m}}$ dissipation and ROS production. In addition, the in vivo studies suggest that bile acids directly or indirectly modulate apoptosis-related protein abundance at the mitochondrial membrane. Finally, the results suggest at least one possible mechanism for the observed beneficial effect of UDCA as a therapeutic agent in the treatment of cholestasis in which increased apoptosis contributes to the pathogenesis of disease.

\section{Acknowledgments}

The authors thank Jeffrey Galecke for technical assistance with mitochondrial isolation and Julie Pribyl for her assistance with FACS analysis. This work was supported in part by a grant from the Minnesota Medical Foundation (to C. J. S.) and by Postdoctoral Fellowship BPD/6082/95 from Junta Nacional de Investigação Científica e Tecnológica, Lisbon, Portugal (to C. M. P. R.).

\section{References}

1. Schmucker DL, Ohta M, Kanai S, Sato Y, Kitani K. (1990) Hepatic injury induced by bile salts: correlation between biochemical and morphological events. Hepatology 12: 1216-1221.

2. Heuman DM, Mills AS, McCall J, Hylemon PB, Pandak WM, Vlahcevic ZR. (1991) Conjugates of ursodeoxycholate protect against cholestasis and hepatocellular necrosis caused by more hydrophobic bile salts. In vivo studies in the rat. Gastroenterology 100: 203-211.

3. Quist RG, Ton-Nu H-T, Lillienau J, Hofmann AF, Barrett KE. (1991) Activation of mast cells by bile acids. Gastroenterology 101: 446-456.

4. Podda M, Ghezzi C, Battezzati PM, Crosignani A, Zuin M, Roda A. (1990) Effects of ursodeoxycholic acid and taurine on serum liver enzymes and bile acids in chronic hepatitis. Gastroenterology 98: 1044-1050.

5. Chazouillères O, Poupon R, Capron J.-P, et al. (1990) Ursodeoxycholic acid for primary sclerosing cholangitis. J. Hepatology 11: 120-123.

6. Poupon RE, Poupon R, Balkau B, and the UDCAPBC Study Group. (1994) Ursodiol for the longterm treatment of primary biliary cirrhosis. N. Engl. J. Med. 330: 1342-1347.

7. Rodrigues CMP, Fan G, Ma X, Brites D, Kren BT, Steer CJ. (1997) A novel role for ursodeoxycholic acid in modulating apoptosis in rat liver, isolated rat hepatocytes and human hepatoma cells. Hepatology 26: 366A.

8. Spivey JR, Bronk SF, Gores GJ. (1993) Glycochenodeoxycholate-induced lethal hepatocellular injury in rat hepatocytes. Role of ATP depletion and cytosolic free calcium. J. Clin. Invest. 92: 17-24.

9. Krähenbühl S, Talos C, Fischer S, Reichen J. (1994) Toxicity of bile acids on the electron transport chain of isolated rat liver mitochondria. Hepatology 19: 471-479.

10. Schaffner F, Bacchin PG, Hutterer F, et al. (1971) Mechanism of cholestasis. 4. Structural and biochemical changes in the liver and serum in rats after bile duct ligation. Gastroenterology 60: 888897.

11. Krähenbühl S, Stucki J, Reichen J. (1992) Reduced activity of the electron transport chain in liver mitochondria isolated from rats with secondary biliary cirrhosis. Hepatology 15: 1160-1166.

12. Imberti $R$, Nieminen A-L, Herman B, Lemasters JJ. (1993) Mitochondrial and glycolytic dysfunction in lethal injury to hepatocytes by t-butylhydroperoxide: Protection by fructose, cyclosporine A and trifluoperazine. J. Pharmacol. Exp. Ther. 265: 392-400.

13. Pastorino JG, Synder JW, Serroni A, Hoek JB, Farber JL. (1993) Cyclosporine and carnitine prevent the anoxic death of cultured hepatocytes by inhibiting the mitochondrial permeability transition. J. Biol. Chem. 268: 13791-13798. 
14. Zamzami N, Marchetti P, Castedo M, et al. (1995) Sequential reduction of mitochondrial transmembrane potential and generation of reactive oxygen species in early programmed cell death. J. Exp. Med. 182: 367-377.

15. Kroemer G. (1997) The proto-oncogene Bcl-2 and its role in regulating apoptosis. Nat. Med. 3: 614620.

16. Xiang J, Chao DT, Korsmeyer SJ. (1996) BAXinduced cell death may not require interleukin $1 \beta$-converting enzyme-like proteases. Proc. Natl. Acad. Sci. USA 93: 14559-14563.

17. Botla R, Spivey JR, Aguilar H, Bronk SF, Gores GJ. (1995) Ursodeoxycholate (UDCA) inhibits the mitochondrial membrane permeability transition induced by glycochenodeoxycholate: A mechanism of UDCA cytoprotection. J. Pharmacol. Exp. Ther. 272: 930-938.

18. Kurosawa H, Que FG, Roberts LR, Fesmier PJ, Gores GJ. (1997) Hepatocytes in the bile ductligated rat express Bcl-2. Am. J. Physiol. 272: G1587-G1593.

19. Koga H, Sakisaka S, Ohishi M, Sata M, Tanikawa K. (1997) Nuclear DNA fragmentation and expression of $\mathrm{Bcl}-2$ in primary biliary cirrhosis. Hepatology 25: 1077-1084.

20. Walajtys-Rhode E, Zapatero J, Moehren G, Hoek JB. (1992) The role of the matrix calcium level in the enhancement of mitochondrial pyruvate carboxylation by glucagon pretreatment. J. Biol. Chem. 267: 370-379.

21. Sokol RJ, Devereaux M, Mierau GW, Hambidge KM, Shikes RH. (1990) Oxidant injury to hepatic mitochondrial lipids in rats with dietary copper overload. Modification by vitamin E deficiency. Gastroenterology 99: 1061-1071.

22. Dupourque D, Kun E. (1969) Cytoplasmic and mitochondrial malate dehydrogenases from beef kidney. Methods Enzymol. 13: 116-122.

23. LaRusso NF, Flower S. (1979) Coordinate secretion of acid hydrolases in rat bile. Hepatocyte exocytosis of lysosomal protein? J. Clin. Invest. 64: 948-954.

24. Beaufay H, Amar-Costesec A, Feytmans E, et al. (1974) Analytical study of microsomes and isolated subcellular membranes from rat liver. I. Biochemical methods. J. Cell Biol. 61: 188-200.

25. Cathcart R, Schwiers E, Ames BN. (1983) Detection of picomole levels of hydroperoxides using a fluorescent dichlorofluorescein assay. Anal. Biochem. 134: 111-116.

26. Carter WO, Narayanan PK, Robinson JP. (1994) Intracellular hydrogen peroxide and superoxide anion detection in endothelial cells. J. Leukocyte Biol. 55: 253-258.

27. Zamzami N, Marchetti $P$, Castedo $M$, et al. (1995) Reduction in mitochondrial potential constitutes an early irreversible step of programmed lymphocyte death in vivo. J. Exp. Med. 181: $1661-1672$.
28. Trembley JH, Ebbert JO, Kren BT, Steer CJ. (1996) Differential regulation of cyclin Bl RNA and protein expression during hepatocyte growth in vivo. Cell Growth Differ. 7: 903-916.

29. Kren BT, Kumar NM, Wang S-q, Gilula NB, Steer CJ. (1993) Differential regulation of multiple gap junction transcripts and proteins during rat liver regeneration. J. Cell Biol. 123: 707-718.

30. Sokol R, Devereaux M, Khandwala R, O'Brien K. (1993) Evidence for involvement of oxygen free radicals in bile acid toxicity to isolated rat hepatocytes. Hepatology 17: 869-881.

31. Bernardi P. (1992) Modulation of the mitochondrial cyclosporin A-sensitive permeability transition pore by the proton electochemical gradient. Evidence that the pore can be opened by membrane depolarization. J. Biol. Chem. 267: 88348839.

32. Fan G, Kren BT, Steer CJ. (1998) Regulation of apoptosis-associated genes in the regenerating liver. Semin. Liver Dis. (In press).

33. Que FG, Phan VA, Phan VH, LaRusso NF, Gores GJ. (1997) Glycoursodeoxycholic acid (GUDC) inhibits cholangiocyte apoptosis: A mechanism of GUDC cytoprotection. Hepatology 26: 255A.

34. Zamzami N, Susin SA, Marchetti P, et al. (1996) Mitochondrial control of nuclear apoptosis. J. Exp. Med. 183: 1533-1544.

35. Newmeyer DD, Farschon DM, Reed JC. (1994) Cell-free apoptosis in Xenopus egg extracts: Inhibition by $\mathrm{Bcl}-2$ and requirement for an organelle fraction enriched in mitochondria. Cell 79: 353364.

36. Kroemer G, Zamzami N, Susin SA. (1997) Mitochondrial control of apoptosis. Immunol. Today 18: 44-51.

37. Miura M, Zhu H, Rotello R, Hartwieg EA, Yuan J. (1993) Induction of apoptosis in fibroblasts by IL- $1 \beta$-converting enzyme, a mammalian homolog of the C. elegans cell death gene ced-3. Cell 75: 653-660.

38. Vayssière J-L, Petit PX, Risler Y, Mignotte B. (1994) Commitment to apoptosis is associated with changes in mitochondrial biogenesis and activity in cell lines conditionally immortalized with simian virus 40. Proc. Natl. Acad. Sci. USA 91: 11752-11756.

39. Ljubuncic P, Fuhrman B, Oiknine J, Aviram M, Bomzon A. (1996) Effect of deoxycholic acid and ursodeoxycholic acid on lipid peroxidation in cultured macrophages. Gut 39: 475-478.

40. Invernizzi $P$, Salzman AL, Szabó $C$, Ueta I, O'Connor M, Setchell KDR. (1997) Ursodeoxycholate inhibits induction of NOS in human intestinal epithelial cells and in vivo. Am. J. Physiol. 273: G131-G138.

41. Kren BT, Rodrigues CMP, Setchell KDR, Steer CJ. (1995) Post-transcriptional regulation of mRNA levels in rat liver associated with deoxycholic acid feeding. Am. J. Physiol. 269: G961-G973. 
42. Yang E, Zha J, Jockel J, Boise LH, Thompson CB, Korsmeyer SJ. (1995) Bad, a heterodimeric partner for $\mathrm{Bcl}-\mathrm{X}_{\mathrm{L}}$ and $\mathrm{Bcl}-2$, displaces $\mathrm{Bax}$ and promotes cell death. Cell 80: 285-291.

43. Boise LH, González-Garcia M, Postema CE, et al. (1993) $B c l-x$, a $b c l-2$-related gene that functions as a dominant regulator of apoptotic cell death. Cell 74: $597-608$.

44. Vander Heiden MG, Chandel NS, Williamson EK, Schumacker PT, Thompson CB. (1997) Bcl- $x_{L}$ regulates the membrane potential and volume homeostasis of mitochondria. Cell 91: 627-637.

45. Yang J, Liu X, Bhalla K, et al. (1997) Prevention of apoptosis by Bcl-2: Release of cytochrome $\mathrm{C}$ from mitochondria blocked. Science 275: 11291132.

46. Kluck RM, Bossy-Wetzel E, Green DR, Newmeyer DD. (1997) The release of cytochrome c from mitochondria: A primary site for $\mathrm{Bcl}-2$ regulation of apoptosis. Science 275: 1132-1 136.

47. Kantrow SP, Piantadosi CA. (1997) Release of cytochrome $\mathrm{c}$ from liver mitochondria during permeability transition. Biochem. Biophys. Res. Commun. 232: 669-671.

48. Susin SA, Zamzami N, Castedo M, et al. (1996) Bcl-2 inhibits the mitochondrial release of an apoptogenic protease. J. Exp. Med. 184: 1331-1341. 